\title{
A CRITICAL UNDERSTANDING AND TRANSFORMATION OF AN INTRODUCTORY STATISTICS COURSE
}

\author{
MARCOS NASCIMENTO MAGALHÃES \\ University of Sao Paulo, SP, Brazil \\ marcos@ime.usp.br \\ MARIA CECILIA CAMARGO MAGALHÃES \\ Pontifical Catholic University, SP, Brazil \\ cicamaga@gmail.com
}

\begin{abstract}
In this paper, we report on the impact of four activities and two interviews on the organization of an introductory statistics course attended by future mathematics teachers at the University of Sao Paulo, Brazil. The activities were designed to enhance students' learning and collaborative knowledge construction, based on Vygotsky's Socio-Historical Theory. Data were collected in the course through the activities and the interviews. Analysis of the data suggests that the course improved students' initiative, collaboration and intentional action, as well as their attitude as future mathematics teachers. Quantitative results comparing 2013 with earlier offerings of the course are also discussed. The transformation discussed here could be applied in other introductory statistics courses, and may lead to practical pedagogical improvements.
\end{abstract}

Keywords: Statistics education research, Statistics concepts; Zone of Proximal Development; Teaching-learning statistics

\section{INTRODUCTION}

In this paper, we examine the contexts created for students' learning and development in an introductory statistics course attended by mathematics education students at the Mathematics and Statistics Institute of the University of São Paulo, Brazil (USP). In Brazil, the teachers responsible for teaching statistical content to students at middle and high school levels usually have a degree in mathematics education which includes statistics courses in its curriculum.

Since the 1990s, the Brazilian Federal Government has introduced guidelines for the basic education system through the National Curricular Parameters (NCP). These guidelines are not mandatory: they bring theoretical-practical suggestions to improve the teaching and learning processes of mathematics. These guidelines are divided into four content blocks at middleschool level and three at the high-school level. Combinatorics, probability and statistics are part of the 'Information Handling' and 'Data Analysis' blocks for middle and high-school levels, respectively. As mentioned in Campos et al. (2011), the implementation of the NCP guidelines faces important challenges, particularly in the area of initial and continuing teacher education.

This paper focuses specifically on ways to enhance students' concept formation in statistics, the development of responsibility for their own and their colleagues' learning, and their professional formation as future teachers. The transformation of the course that is described was aimed to create collaborative contexts for intentional and active involvement of students in large classes, based on Vygotsky's discussion of Socio-Historical Theory. This theoretical frame will support our discussions of the results revealed, among others alternatives, by content analysis of videotaped data from interviews and of classroom moments.

The paper is organized as follows: Section 2 presents the theoretical background; Section 3, the methodological frame; Section 4, the analysis; Section 5, the results and final remarks.

Statistics Education Research Journal, 13(2), 28-41, http://iase-web.org/Publications.php?p=SERJ (C) International Association for Statistical Education (IASE/ISI), November, 2014 


\section{THEORETICAL BACKGROUND}

This section's objective is to discuss both the theoretical concept of teaching-learning and development based on Socio-Historical Theory (Vygotsky, 1934/1987), and the teachinglearning of statistics.

\subsection{SOCIO-HISTORICAL THEORY}

Vygotsky (1934/1987) discusses human development as a socio-cultural-historical activity in which individuals learn by interacting with others in the contexts of their experiences. As he points out, human development is a continuous and active social, cultural process of internalization of ideas, values, concepts, and language organization which allows individual subjects to construct new meaning while interacting with others. In this process, what is actually internalized by the participants is whatever is constructed in the dialogical and dialectical interactions. The focus is, therefore, on social and collaborative negotiation, rather than on individual construction.

As one can infer from the above, establishing collaborative contexts is quite important and complex, since it comprises much more than just organizing a space so that participants can sit together, much more than simply taking part in a discussion or in any other work in cooperation with others. Dialogues must be defined by inter-agents collaborative actions, by participants' carefully listening to each other, so that probing misunderstandings (or diverging ideas) and developing new ways to think and act is made possible. In other words, the context organized (not a priori - since it is not simply a matter of physical position or proximity) must allow participants to engage in a course of action in which co-building is made possible and in which they feel comfortable to show their different understandings and difficulties, differing points of view, and issues they consider problematic - thus making the dialogue meaningful for everyone.

In this paper, we are studying the teaching-learning in a college context that is typically characterized by individualism, classes with large number of students, and utilizing a teachinglearning methodology often characterized as a functional means to achieve a pre-determined end. As discussed by Newman and Holzman (1993), a clear description of this milieu is central to the comprehension of the results of this investigation, since results cannot be understood separately from their context. Vygotsky's concept of Zone of Proximal Development (ZPD) is important for understanding the process of organizing language mediation of dialectical relations, by means of intentional actions to share and transform realities (Newman and Holzman, 1993, p. 100). In Vygotsky's words (1934/1987, p. 209), research indicates that "the zone of proximal development has more significance for the dynamics of intellectual development and for the success of instruction than does the actual level of development" (italics in original). The focus is on creating collaborative contexts that might allow learning to take place-not only the learning of a specific content, but also appropriating new understandings related to how to think and act. It is about creating contexts in which cognitive and affective conflicts are not separated from each other, i.e., all participants act in order to listen to each other and to be responsive to each other's actions, while being responsible for their own actions. That is, it is through collaborative mediated actions that individuals appropriate cultural artifacts that allow them to learn and develop. In Vygotsky's (1931/1997, p. 105) words, “... we might say that through others we become ourselves".

Central to this discussion is the concept of agency as the intentional nature of human actions to reach a specific aim, in joint work, that creates a potential for transformation, as discussed by Engeström (2011). That is, students perceive the transformative power of intentional actions while working with colleagues and instructor to solve problems in specific contexts. Edwards (2009) stresses the importance of agency in collaborative work. She discusses the concept of "relational agency" as the capacity to offer support and to ask for support from others. 
These are central concepts to our discussion in this paper that focuses on the need for new ways to create collaborative work in large classes, in which students gain confidence in development of statistical concepts by offering and receiving support. When discussing the process of scientific concept development, Vygotsky (1934/1987, pp. 132-133) stresses as fundamental the individual's mastery of their own mental process, and the central importance of joint work for the appropriation of new ways to think and act in the world, in interactions mediated by cultural artifacts. Vygotsky's discussion provides a theoretical-methodological comprehension of ways to conduct research in large classrooms in order to create contexts for learning and development.

In the same direction, Garfield and Ben-Zvi (2008) discuss the teaching-learning of statistics as a process in which theory and practice are interdependently related. As the authors argue, teachers need to create in classrooms a collaborative context in which teachers themselves and students jointly construct meaning, rather than just listening and completing set tasks.

In large university classes such as the one we are discussing in this paper, the creation of collaborative learning environments is a complex task for diverse reasons. Students have already constructed a historical-cultural comprehension of what it means to act as a student in the specific university context. This involves the idea that they do not need to be responsible for taking an active role in class, but only to understand the professor's explanation and to hand in set exercises. This paper is based on a diverse theoretical and methodological basis that stresses language organization as central to creating mutual ZPDs, so instructors can learn about students' learning processes and students, by engaging in dialogical argumentative discussions with colleagues and the instructor, may learn how to develop creative ways to use statistical concepts in discussion. In this critical-collaborative process, all participants teach to and learn with each other, and become responsible for sharing meanings that will promote the appropriation of new ways to relate the theoretical concepts to practical uses. It is important to say that learning, for Vygotsky, does not always lead to development, since- as pointed out by Stetsenko (2011, p. 167) - it "has to do with people collaboratively transforming their world in view of their goals and purposes - a process through which people come to know themselves and their world..."

\subsection{THE TEACHING-LEARNING OF STATISTICS}

The objectives of the course discussed in this paper are similar to other university introductory statistics disciplines and could be summarized as statistical literacy and development of statistical reasoning, as defined in delMas (2002). According to Garfield and Ben-Zvi (2008), in addition to the focus on the concepts to be appropriated by the students, it is also important to support future mathematics teachers in their job of teaching statistics. To this end, they provided a comprehensive review of research studies in disciplines that contain statistics at college level. In their words (p. 42):

There has been a tremendous increase in research studies focused on teaching and learning statistics and probability over the past 15 years. These studies continue to span many different disciplines and differ in focus, theory and methodology, and supporting literature.

However, when revised together, they suggest the difficulties students have learning statistics and the need to revise traditional methods of teaching. The most recent studies on the development of particular types of learning outcomes and reasoning about special topics offer many implications for change in curriculum and teaching methods. However, there are still many open questions and much work is needed to offer more specific guidance to teachers of statistics.

In a more specific Brazilian context, Silva (2011) studied the curriculum and pedagogical projects, related to the probability and statistics content, of seven national institutions that offered a degree in mathematics education. The author discussed the National Curriculum Parameters (NCP) guidelines and criticized the way that disciplines are offered without specific connection with the content of basic education classes. Further, Viali (2008) sampled 125 mathematics education programs in Brazil and studied their curriculum. The statistics content 
in all the programs represented, on average, only $4.7 \%$ of the overall coursework time. A typical discipline would include around 60 hours of probability and statistics classes per semester. The author concludes that not only the quantity, but also the quality of the disciplines must to be improved to give support to mathematics teachers in their job of teaching this content.

Looking at the preparation of universities, Pamplona $(2009,2010)$ did a qualitative analysis of teaching practices based on the opinion of five experienced instructors. According to him, statistics instructors in various disciplines offered in mathematics education programs should have a good specific statistical knowledge and an educational approach that integrates the discipline with the specific program objectives. According to Louzada et al. (2010), it seems that Brazil will have difficulties in the next few years to provide enough PhDs in statistics to meet the expected demand. This situation will influence the quality of the statistics in various disciplines offered in mathematics education programs.

\section{METHODOLOGICAL FRAME}

\subsection{GENERAL CONTEXT}

A degree in mathematics education can be issued from a public or a private university. In Brazil, there are usually important differences between them in terms of learning conditions, student body, and staff qualifications that might affect the education of these professionals. We will not discuss these issues here since, in this paper, we are discussing a statistics course offered in a public university - the University of Sao Paulo, which is free of tuition fees. Students' admission is based on a score obtained in examinations arranged for this purpose, covering high school content. There are different levels of competition depending on the particular career; those with better public recognition, in terms of wages or prestige, will have more competitive entry. Unfortunately, a teaching career does not arouse great interest from young people, as noted by Gatti, Tartuce, Nunes, and Almeida (2009).

Gatti's study includes a survey of 1501 Brazilian students from high schools, 10 public and eight private schools, collected in seven Brazilian States from all regions of the country. The survey was followed by interviews with students and roundtables with vocational specialists. From the results of the survey, only $2 \%$ of the students chose, as first option, a teaching career.

In 2013, at University of Sao Paulo, for mathematics and physics teaching careers at the Sao Paulo city campus, there were 2.81 candidates for each available place (FUVEST, 2013). This was one of the lowest levels, in a range from 2.23 for Natural Science Bachelor Degrees (the lowest level) up to 56.4 for Medical Degrees (the highest). As a consequence, the mean entrance score was 48.2 points (on a scale up to 100) for the mathematics education daytime course, compared to 80.2 points for a medical career. Roughly speaking, the mean global score for entrance reflects the incoming students' scientific and cultural backgrounds.

\subsection{COURSE CONTEXT}

The curriculum leading to a qualification in mathematics education at USP in the São Paulo city campus contains two semesters of statistics. The discussion in this paper is focused on the first of these. The syllabus includes combinatorics, descriptive statistics, probability and discrete random variables, taught during two 100-minute classes per week. Data were collected in the first semester (March to June) of 2013. The discipline had 75 students enrolled at the beginning of the semester, and for most students it was their first semester at the university.

Students in this class generally had a weak mathematics background, which reflects their previous schoolwork and affects their learning processes in the discipline. In a voluntary survey collected at the beginning of classes, $63 \%$ of the students declared that their previous knowledge of statistics was 'poor'. We observed that several students had problems with comprehension while reading statistical problems, as well as with effective studying methods.

Additionally, it is worth mentioning the existence of time constraints. The survey already cited showed that nearly $50 \%$ of students in the class had professional jobs, in general requiring 
4-8 hours of work per day. Being located in a large city requires time to come and go to the workplace. On average, going to the university took 75 minutes, with a standard deviation of 40 minutes; there were a few students who spent five hours per day in transit. This was reflected in the time available for studying, an average of 10 hours per week with a standard deviation of seven hours per week.

During class, some lectures were given in the traditional style - knowledge was transmitted by the teacher. However, all of them were organized to involve the students by means of critical questioning or problem solving. As indicated in Rossman's address at the International Conference on Teaching Statistics 8 (Rossman, 2010), asking questions that might guide students to develop their understanding is important. Further, students' answers may reveal their process of concept internalization. That is, students' concept formation will be revealed by the externalization process, as discussed by Socio-Historical Theory. However, as the students were not yet familiar with the instructor, it was not easy to elicit answers from students at the beginning of the course. Later on, as we tried to create a friendly environment, students started to demonstrate their comprehension of concepts or ask questions to reveal their doubts. However, there is a kind of 'tradition of silence' in the mathematics classes on which students' affective-cognitive actions in the classroom are based - the fear of being considered an incompetent or lazy student.

\subsection{DATA COLLECTION}

Next we will briefly describe the four activities and two interviews on which the data to be analyzed are based.

Activity 1: Students' reading in advance of class. We usually asked the students to read the material to be worked on during class, prior to the class itself. In general, the texts were either 5-6 pages of provided material, or material from the textbook.

Activity 2: Brainstorming and writing. In the beginning of the descriptive statistics topic, we asked each student in class to indicate the first word that came to his/her mind when the word statistics was said. The instructor asked students to write a text for the next class that included the words mentioned. Such writing aimed to motivate reflection about statistics and its connections with society.

Activity 3: Project 1. We asked students to organize themselves in groups, and choose a theme they wanted to investigate based on an available data set. The data came from a survey collected during the 2012 and 2013 classes, and included several items related to students' lives. Students were asked to work on their chosen theme, to write a report, and to present the results to the class using multimedia resources. The presentations, including a discussion in class about the project, were partially videotaped.

Activity 4: Project 2. The organization of the class - working in groups - was similar to Project 1 . However, in Project 2, students were asked to prepare a practical activity to be used in middle or high school classes. They could choose the subject from topics discussed in class, and the activity could be created by the group or adapted from an existing one. They prepared the report and a poster presentation for the class.

Interviews 1 and 2. Two interviews with students were organized. The first interview occurred three weeks after the beginning of the semester with six participants, randomly selected from the class. The second interview, at the end of the course, included six students, four of them participants in the first interview. Two students had left the group and two others had joined voluntarily. In the second interview, three of the participants had succeeded in the

course while the other three had failed. The objective was to understand students' points of view about the classroom organization regarding their learning and development. These interviews were videotaped. 


\section{ANALYSIS}

In this section, we will describe and discuss each activity. The interviews helped our discussion concerning students' points of view on the issues analyzed. Data were analyzed looking for results on creating collaborative contexts to involve students in large classes in order to enhance:

- students' appropriation of statistics concepts;

- students' professional education concerning the relationship between the concepts learned and the teaching of statistics at school.

\subsection{ANALYSIS OF ACTIVITY 1 - STUDENTS’ READING IN ADVANCE}

The class meetings occurred twice a week and, in general, the instructor asked the students to read a few pages to prepare for the next meeting. The reading material was available to students through handouts or the textbook. However, as we have mentioned, as well as time constraints, students were not usually experienced with reading texts to be discussed in class.

As a motivation for the reading tasks, it was common that the instructor finished the class with a question whose answer would be obtained from the assigned reading. For instance, to motivate the reading about dispersion measures, the instructor computed measures of location for one variable in three different data sets. The values of mean, median and mode were the same, not only inside each set but also in all three data sets. A question was asked: Is the behavior of the variable identical in all data sets? If it is not, what is missing? In another example, just before introducing the concept of independence of two random variables, the instructor questioned the class about the possibility of obtaining the joint probability function from the known marginal probabilities.

Usually, the instructor initiated classes by asking who had read the assigned material. A small discussion followed on issues and concepts in the text. After the topic presentation, students were asked if the previous reading had enhanced their understanding of the content. Typically, two or three students expressed their opinions, highlighting the advantage of the reading in advance.

The preparatory reading aimed to create a context for learning and development of the statistical concepts, as indicated in Vygotsky`s writings. The aim for creating such a context was twofold: to enhance students' reading capacity, and to provide them with a cultural artifact that would foster their intentional action in collaborative classroom work, as stressed by Vygotsky`s definition of zone of proximal development (ZPD). The instructor would then be able to involve the class in raising their doubts and in expanding their colleagues' questions and answers. As pointed out by Edwards (2009), students act to offer or request support during classroom practice. Creating such a relational process, mediated by cultural artifacts (to which language is central), aimed to involve students in collaborative action to share and construct meaning; this places instruction in the ZPD, as discussed by Vygotsky $(1987,1997)$ and also by Garfield and Ben-Zvi (2008).

Below we present some excerpts from the two interviews that reveal students' views about preparatory reading for statistical concepts learning.

From the first interview:

T: [Reading in advance] it's better. It [the classroom lecture] is not the first contact. When you have already got in touch with the subject you have an idea, it helped a lot.

VH: As she said, I think it works as an introduction to the subject. There was a part in the book "What is Statistics" which had examples and illustrations. In class, when the subject was discussed, it became clearer.

J: I also think it helps. I was guilty because I only remembered to read during the trip to the university, in the metro or bus. But I realized it helped a lot. 
From the second interview:

VS: Reading before class helps so you do not get lost. I compared the days I did not read with the ones I had read. I realized that my understanding was worse these days [the ones I did not read].

A: It is always important to come to class with some ideas about the content. It is easier to understand the terms that will be used. If you arrive and you do not know what is under discussion, you wonder what the instructor is talking about. We were not trained for it [reading in advance], it is not a habit, we just sit and see what is going on in the class and then we will try to understand. For new content it [reading in advance] is very important.

$\mathrm{J}$ : It is very important to raise doubts.

F: I agree with everyone, but I couldn't always read. When I read, it helped.

L: Actually, the book support is essential. At the beginning of the course I read the text and examples and I came to class knowing what was going to be discussed. If the instructor proposed a different exercise, I tried to work on it. From the middle of the course on, I did not have time to read. During class, there was for me a huge question mark. I tried to read later at home, but many times things did not get clear. Now, I see it did not work (the student failed). It is essential to come to class with, at least, some idea of what will be discussed.

Students' comments above reveal that reading the content in advance improved their understanding of the concepts to be discussed. It enhanced their confidence to participate in class, answering or formulating questions, raising doubts, and understanding the relationships between theory and practice to work with the new exercises proposed by the instructor. As all of them pointed out, previous reading gave them at least some understanding of the concepts to be discussed, and it is central to concept formation since it creates a context for collaborative action in classroom discussion. However, as A (Interview 2) says and J (Interview 1) exemplifies, their previous experiences at school did not prepare them for this. Besides, as VS (Interview 2) reveals, although they knew the importance of previous reading, they may not have had the time. The comments reveal students' appropriation of preparatory reading as an intentional mediational means (cultural artifact) for concept formation that creates a potential for transformation (Engeström, 2011), since it expands the ways they act.

The experience with this activity revealed a need for balanced pressure and incentive for task completion. Sometimes a quick quiz was given to check students' previous reading. However, the instructor's adherence to the task almost every week, even with the initial low participation, was central for the understanding of its importance. Students' frequent testimony that reading had improved their understanding was important for the fact that, by the end of the semester, the majority of the class participated in this task.

\subsection{ANALYSIS OF ACTIVITY 2 - BRAINSTORMING AND WRITING}

The objective of Activity 2 was to create a context to involve students in joint work to reflect on their experiences with statistical concepts, their practical use, and their connections with society and everyday life, as bases for construction of new meaning. As discussed by Stetsenko (2011, p. 167), through this process "people come to know themselves and their world", which puts instruction in a ZPD, providing students with the context to relate statistical concepts to society.

From the brainstorming session on statistics, ten words were reported: sample, quantifying, survey, graphic, analysis, table, information, probability, estimation and percentage. Students' writing involving these words showed different qualities. Some of them revealed internalization of the concepts and creative expansion based on further reading. Others related different aspects of real life and personal experiences to statistics and a few of them were quite creative.

Most of them put forward the idea of statistics as a support in the decision-making process. The concept of sampling to obtain information about populations, and the use of graphs and tables as expressions of a data set were mentioned in several reflections. However, there were 
writings in which the concepts of probability, percentage and estimation were not used in coherent ways. We highlight some excerpts from the students' reflections:

Related to the teacher's job, a student wrote: “... If we want to be good teachers we cannot allow topics to be taught without quality. It is necessary to know what we are talking about. Then, more than numbers, statistics opens our mind to a new way in which numbers mean data, information, percentages, etc..."

One student created a fictitious dialog between two scientists in a laboratory testing a new diet on animals. The scientists were discussing the latest results using graphs and tables. One of the scientists suggested, as a final research step, testing on humans. In this way, he recommended contacting the university administration in order to use the central student restaurant at the university. This writing was possibly motivated by complaints about the quality of the food served in that restaurant.

There was also a love letter: "... if it would be possible to do an estimation of the number of grains of sand on a beach, this would be the number of days I want to be at your side..." Another student set up an analogy between vegetables and statistics. Among other points, he mentioned that vegetables are indispensable for the body, as statistics is indispensable for several careers. After receiving the reflections, the instructor led a discussion focusing on misconceptions or misinterpretations.

In this activity, the instructor created a possibility for students to interact in collaborative ways to identify words related to statistical concepts, to work individually in a writing assignment to relate the words to society, and to reflect jointly on misconceptions and doubts revealed by the writing task. We would say that a ZPD was created, since instruction focused beyond what students already knew and enhanced the process of internalization of statistical concepts concerning community issues and everyday problems, as discussed by Garfield and Ben-Zvi (2008). In addition, students realized that mathematics is not opposed to writing, and a well-written reflection can help learning of complex mathematical concepts.

\subsection{ANALYSIS OF ACTIVITY 3 - PROJECT 1}

This activity aimed at the externalization process (Vygotsky) of statistical tools in real contexts, i.e., to create contexts so students could relate theory and practice while they experienced working with research questions based on a real data set. It created a context for group collaboration to prepare the activity, which included a written report and an oral presentation, and class discussion.

The students were given a data set that had been collected from students of the 2012 and 2013 classes, through a questionnaire whose variables were based on the students' interests. The content included biometric data such as weight and height, and personal information such as gender, age, home region and school background. Other variables were time spent on transit between home and university, time spent using the internet and studying. There were questions on prior knowledge of statistics and on reasons for pursuing a teaching career in mathematics. Answering the questionnaire was voluntary and resulted in a total of 212 observations with 49 of them from the 2013 class.

It is important to mention that in the curriculum of Mathematics Education, the next (second) course in statistics covers the topics of sampling and inference; in that course students will have the experience of preparing and administering a questionnaire, as well as analysis of the resulting data, which is covered in both courses.

The students spent around three weeks preparing for Activity 3, which included a written report and an oral presentation. A first point discussed in class was the necessity to clean up the data set. It is common, mainly in open questions, to obtain nonsense records or mistakes from typos or measurement errors. It was important for students to face these situations, deciding whether to use or discard problematic observations. They organized groups of three to six participants, and chose the theme they wanted to study using the given data set. The groups could complement their research using other sources of information such as newspapers, internet and scientific journals, and any software for data analysis that they wanted, such as spreadsheets and R. 
When the project was started, the course content had not yet included mean, mode or variance. They were supposed to use frequency tables, graphs such as histograms and boxplots, and quantiles. Our intention was to reinforce the fact that good analysis could also be made using simple tools such as graphs and tables. We tried to avoid the usual summary statistics without any further comments or analysis. Nevertheless, a few groups did use them, and it was an opportunity to discuss some resulting misconceptions. There were 12 groups with a variety of themes, such as: age differences and school background; body mass index (BMI) according to gender; transit and study times; educational background and job situation.

After each oral presentation, there was time for questions and comments. At the end of each presentation the instructor led a general discussion. From the reports and oral presentations, we observed that the majority of the students made use of frequency graphs, boxplots, and tables to represent the data set. Several groups presented clear conclusions based on these tools, while others had some difficulty presenting their ideas, making some mistakes in the graphs and tables.

The general discussion (which was videotaped) focused on the conclusions that each group had reached and their use of statistics in the task. A lively discussion occurred about the quality of public and private schools. Since many groups worked on themes related to school background, several students were 'statistically' prepared to present their arguments based on concrete data. For instance, some groups used the information about students' participation in preparation courses for the university admission exam as an indicator of the absence of quality in middle and high schools. They compared results from public and private schools to obtain their conclusions. Concerning the statistical issues, students emphasized the importance of graphs in representing data, and reported on their group discussions about which graph to use in each case. Here is a selection of other comments from the discussion:

- Working in groups is hard, but it is a good way to learn.

- I learned a lot with the group work.

- With graphs, conclusions show up.

- My group worked with an open question and we did not like the way the answers were categorized.

- Numbers and analysis surprised us, sometimes contradicting previous conceptions.

- It is different from exercises, in the project we had to chose the ways to go.

- I was disappointed; in math exercises there is an 'exact right answer' but in the statistics project there is not.

- Statistics is powerful because it summarizes information, but it is dangerous because there is a need for correct interpretation.

This project created contexts for collaborative work at several points: the group choice of the theme, the report writing, the oral presentation and the class discussion. They all involved ways to think and act that, due to the diverse experiences of the participants, might have created cognitive and affective conflicts central to development. The previous comments express these conflicts, for instance, "Working in groups is hard, but it is a good way to learn". We would say that the activity created possibilities for collective learning, potential for the participants to move from what they know and can do by themselves to what they can develop as a group. In other words, it created ZPDs to transform participants' agency. Group participants had to learn how to listen to others and to be responsive to the actions of others, as well as to be responsible for their own actions.

In general, students' participation was good in all the steps of the activity. They had the opportunity to apply statistics to real data and an initial lesson in statistical reasoning. They had to evaluate arguments and opinions and articulate limitations on their conclusions. A suggestion for a future offering of the course would be for groups to revisit their projects to incorporate statistical ideas discussed later in the course. 


\subsection{ANALYSIS OF ACTIVITY 4 - PROJECT 2}

The objective of Project 2 was to create context so that students could, through practical activities, relate the concepts learned in the course to the ones they would be expected to teach in middle and high-school classes. The groups could be the same as in project 1, though there were some changes.

The task for each group was not just preparing a good exercise. They were expected to create or adapt a practical activity to produce an active learning activity, as discussed by SocioHistorical researchers. The instructor gave general guidelines and the groups had four weeks to complete their task, which included writing a report and preparing a poster presentation to the class. Students' reports had to include the support material and the school level at which the activity would be applied.

The 10 groups prepared activities in combinatorics and probability (such as choosing clothes and selecting a volleyball team), data collection (such as people's music preferences), and measures of location (such as a modified dominos game, and a three-card game).

The poster presentation occurred in a classroom. Each group had five minutes to present their poster and to invite their colleagues to visit it. The instructor visited all posters, asking questions, making comments, and assigning grades.

The choice of topics revealed students' learning and preferences. The most frequent topics were combinatorics and probability using the multiplication principle and the concept of probability trees. An interesting discussion on conditional probability was presented by a group looking at the 'game of the goat (doors)'. In the poster session, they invited other students to play and after five or six rounds they explained the best strategy by showing the sample space on a probability tree.

Two activities on distribution showed innovative characteristics. A 'modified domino game' used measures of location to link the pieces. Each piece had one side with one number and the other side with three numbers. The player had to compute a central tendency measure in order to link the pieces, and the game could be set to different levels of difficulty. Using a deck of cards, another group proposed a 'three card game' in which each player aimed to discover the three hidden cards they have been assigned. The cards are placed on the head of each player so that they can be seen by all other players. Players asked questions in turn about the mean, range or other measures in order to get information about the hidden cards, and they can take notes about the answers given. The game can be modified in several ways, for instance, by allowing other questions or limiting their number. Basically, these two games only required the player to compute summary measures, but they organized the content in a new and creative way.

Participation was intense during the poster presentation. The students visited the posters, asking questions and taking part in the practical activities proposed. They discussed how well the activity would work in a Brazilian school class. It was obvious that the groups were quite proud of their work and for several students it was their first experience of thinking as a teacher.

Project 2 created a context for the externalization of the statistical concepts internalized through classroom practices by carrying out an activity in which students had to work with colleagues collectively to create or adapt a practical activity to produce an active learning activity. The proposed task also focused on creating contexts for learning and development through students' collaboration.

Project 2 requires participants to evaluate the mastery of their own mental processes concerning the scientific concept chosen, in order to develop their exercise, organize their poster and to discuss their work with colleagues during poster visiting. As Vygotsky (1934/1987) suggests when discussing the process of scientific concept development, this process is central to concept formation. It takes place in collaborative work provided by classroom instruction in which, as stressed by Garfield and Ben-Zvi (2008), learning and development occurs, when ZPDs are created as collective ways of working together. 


\section{RESULTS}

In order to evaluate the overall results of the course, we used qualitative analysis and quantitative comparisons with previous offerings of the same course. Improvement in this version of the course seems to be more evident in students' attitudes than in their quantitative results, which are presented next.

\subsection{QUANTITATIVE RESULTS}

The same instructor had taught the initial statistics courses since 2011 and, in all of them, the final grade was calculated from results of exams and exercises. Aside from the different activities introduced, we used much the same criteria to attribute the grades. Furthermore, data available from the University Admissions Office (FUVEST, 2013) do not reveal any clear difference in the students' background during these three years.

We now present comparative results from 2011 to 2013. Figure 1 presents the boxplots of the final grades, with means and standard deviations shown in the horizontal labels. There were outliers in all years, but the general picture indicates only small changes from year to year.

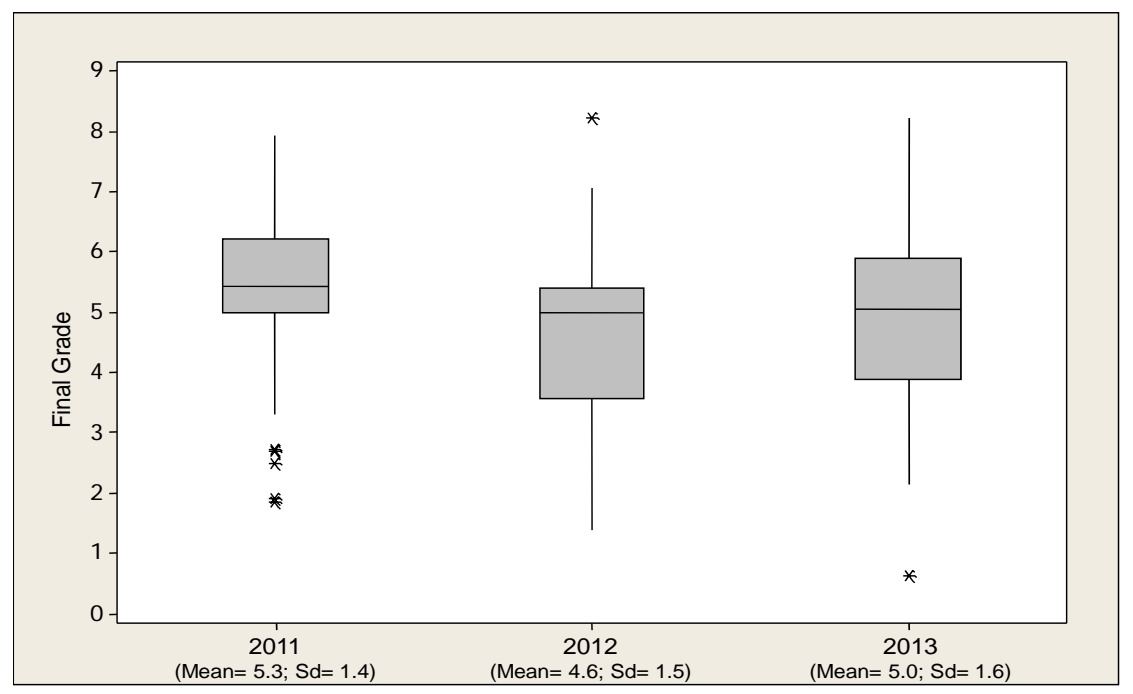

Figure 1. Final grade.

Table 1 summarizes other numerical information related to the course over the last three years. To pass, students must reach a final grade of 5 or over on a scale of 0 to 10 . Again, the results indicate only small changes from year to year.

Table 1. Comparative results on different editions of the statistics course

\begin{tabular}{ccccc}
\hline Year & Enrolled & Dropout Rate & Pass Rate* & $\begin{array}{l}\text { Final Grade mean (sd) } \\
\text { passing students }\end{array}$ \\
\hline 2011 & 67 & $28 \%$ & $77 \%$ & $5.9(0.8)$ \\
2012 & 66 & $32 \%$ & $56 \%$ & $5.6(0.8)$ \\
2013 & 75 & $28 \%$ & $65 \%$ & $5.9(1.0)$ \\
\hline
\end{tabular}

*The percentage was computed excluding the students that dropped the course.

To explore the comparison between 2011 and 2013 in a bit more depth, we have used one identical question posed in both years on the issue of distributions: Are there differences between random and empirical variables? In 2011, students answered the question in a quick class quiz (that could be taken in pairs); in 2013, the question was presented in an exam (taken 
as individuals). In 2012, we used different questions to assess this topic. Table 2 presents the percentage of answers classified into three levels: not satisfactory, partially satisfactory, and satisfactory. Again, we observe a small (though non-significant) improvement in 2013 compared to 2011, reinforced by the conditions in which the answers were produced in 2013. In fact, there were several assessments in the course that required knowledge of distributions; this analysis is reported here as it was one of the most important assessments of this topic.

Table 2. Percentage results on a question about distributions

\begin{tabular}{ccccc}
\hline Year & $n$ & Not satisfactory & Partially satisfactory & Satisfactory \\
\hline 2011 & 41 & $32 \%$ & $46 \%$ & $23 \%$ \\
2013 & 34 & $26 \%$ & $35 \%$ & $39 \%$ \\
\hline
\end{tabular}

In short, the 2013 course had somewhat better results when compared to 2012, while the comparison between 2011 and 2013 shows mixed results.

\subsection{QUALITATIVE RESULTS}

Looking at qualitative results in the 2013 edition of the course, we observed several improvements based on the interviews, discussions and teacher's observation of the activities in class. The main points are summarized below.

Approach to learning mathematical content As the students mentioned in the first interview, they had transformed the way to solve problems in combinatorics and moved beyond the simple mechanical use of formulas. According to them, they now try to understand the concepts not only to repeat exercise solutions, and this gives them more confidence in themselves as learners. In both interviews, students emphasized the reading in advance (Activity 1) as important to learning.

Collaboration with colleagues In the second interview, students mentioned that they had learned from other students' questions in class. During the general discussion on activity 3, students pointed out that collaborative group work was important for learning the concepts presented in class. The students' voices reveal that they have experienced the importance of collaboration to learning, which will affect their future practice as student and teacher.

View of Statistics With Activity 2 (brainstorming), the students had the opportunity to make sense of words related to statistics. The variability presented in the data set used in Activity 3 helped students to consider what is statistics, as mentioned in the general discussion of this activity. From the second interview, students seemed to have improved their understanding of the distinction between actual data and models. The issues above show development of statistical concepts that will be deepened in the second statistics course.

Attitude as a student and future teacher From the second interview, students pointed out important approaches for their academic life. They mentioned that getting a good grade in the examination is not everything, since it is important to understand the concepts. In their role as future teachers, they pointed out the importance of attending the lectures to observe how teachers act, even without a strict enforcement of attendance. They stated that course assessments played a central role in guiding them to the important aspects of the course. From the poster session in Activity 4, they had the experience of acting as teachers, explaining and discussing their work.

These qualitative results were also observed among students who did not succeed in the course. Certainly, most of these new attitudes will not be needed in more traditional courses, since the students' roles will be more passive. In this way, students' roles in different courses produce a contradiction which they will have to reflect upon as part of their professional formation. 


\section{FINAL REMARKS}

Based on Socio-Historical and Statistics Education discussions, we have introduced a series of activities that aimed to create environments (ZPD) for learning and development of statistical concepts. These activities were designed to enhance the relationships between theory and practice. Further, they gave the students the opportunity to develop theoretical and practical activities with colleagues, which is important for their future work as teachers. Class discussions were important moments to learn from their colleagues. Therefore, the course organization was central to creating a collaborative atmosphere.

In the last few years, one of the authors has been teaching introductory statistics courses for future mathematics teachers, knowing that the domain of statistical concepts is important for their work in middle and high school. Despite the changes described and discussed here, we did not leave out any statistical content in 2013 originally planned to be discussed in the course.

As we saw in Table 1, there are undesirable numbers to overcome, such as dropout and pass rates. The challenge to enhance the course remains, but it appears that the activities implemented in 2013 have improved the students' initiative, collaborative and intentional action, as well as their attitudes as future mathematics teachers.

The approach discussed in this paper could be applied by teachers of introductory statistics courses anywhere, and particularly with such courses for students who plan to become mathematics teachers. The approach has a firm theoretical basis in the ideas of important pedagogical theorists. Nothing in the activities described presents any problems that could not be overcome in any other context. All statistical content planned for the course was included and there is some evidence that the approach used improved qualitative outcomes for students.

\section{REFERENCES}

Campos, T. M. M., Cazorla, I. M., \& Kataoka, V. Y. (2011). Statistics school curricula in Brazil. In C. Batanero, G. Burrill \& C. Reading (Eds.), Teaching Statistics in School Mathematics - Challenges for Teaching and Teacher Education. A Joint ICMI/IASE Study: The $18^{\text {th }}$ ICMI Study (pp. 223-234). New York: Springer.

delMas, R. C. (2002). Statistical literacy, reasoning, and learning: A commentary. Journal of Statistics Education, 10(3).

[Online: http://www.amstat.org/publications/jse/v10n3/delmas discussion.html]

Edwards, A. (2009). From the systemic to the relational: Relational agency and Activity Theory. In A. Sannino, H. Daniels, K. D. Gutiérrez (Eds.), Learning and expanding with Activity Theory (pp. 197-211). New York: Cambridge University Press.

Engeström, Y. (2011). From design experiments to formative interventions. Theory \& Psychology, 21(5), 598-628.

FUVEST (2013). Relatórios estatísticos da Fundação Universitária para o Vestibular [Statistical reports of University Foundation for Admission Exam].

[Online: http://www.fuvest.br/estat/insreg.html?anofuv=2013 ]

Garfield, J. B., \& Ben-Zvi, D. (2008). Developing students' statistical reasoning: Connecting research and teaching practice. New York: Springer.

Gatti, B. A., Tartuce, G. L. B. L., Nunes, M. M. R., \& Almeida, P. C. A. (2009). Atratividade da Carreira Docente - Relatório Final [Attractiveness of a Teaching career - Final Report]. São Paulo: Fundação Carlos Chagas.

Louzada, F., Ara, A., Oliveira, C. Z., \& Gonçalves, C. V. (2010). Diagnóstico do Ensino da Estatística nas Universidades Públicas Brasileiras: uma descrição de algumas dimensões que compõem o perfil do seu corpo docente [Diagnostic of teaching statistics in Brazilian public universities: description of dimensions of the profile of their faculty staff]. Revista Brasileira de Estatística- IBGE, 71(234), 7-42.

Newman, F., \& Holzman, L. (1993). Lev Vygotsky revolutionary scientist. New York: Routledge-Taylor \& Francis Group. 
Pamplona, A. S. (2009). A formação Estatística e Pedagógica do professor de Matemática em comunidades de prática [Statistical and Pedagogical formation of Mathematics teacher in practical comunities] (Unpublished doctoral dissertation, University of Campinas, Banco de Teses, Unicamp, Brazil).

Pamplona, A. S. (2010). A formação estatística do professor de Matemática: a importância da utilização de problemas com enunciados sócio culturalmente contextualizados [Statistical formation of mathematics teachers: the importance of problems with socio-cultural contextualized statements]. In C. E. Lopes, C. Q. S. Coutinho, \& S. A. Almouloud (Eds.), Estudos e Reflexões em Educação Estatística (pp. 231-244). Campinas: Mercado de Letras.

Rossman, A. (2010). Ask good questions. International Conference on Teaching Statistics 8, IASE, Ljubljana, Slovenia. [Online: http://statweb.calpoly.edu/arossman/AskGoodQuestionsICOTS.ppt ]

Silva, M. A. (2011). A presença da Estatística e da Probabilidade no currículo prescrito de cursos de Licenciatura em Matemática: uma análise do possível descompasso entre as orientações curriculares para a Educação Básica e a formação inicial do professor de Matemática [Statistics and Probability presence in the curriculum of Mathematics Education career: analysis of possible mismatch between the curriculum instructions for basic education and the initial formation of Mathematics teachers]. Bolema, 24(40), 747764.

Stetsenko, A. (2011). From Relational Ontology to Transformative Activist Stance on Development and Learning: Expanding Vygotsky's (CHAT) Project. In P. E. Jones (Ed.), Marxism and education: Renewing the dialogue, pedagogy, and culture (pp. 165-192). New York: Palgrave Macmillan.

Viali, I. L. (2008). O Ensino de Estatística e Probabilidade nos Cursos de Licenciatura em Matemática [Teaching Statistics and Probability in disciplines of Mathematics Education career]. Anais do SINAPE-Simpósio Nacional de Probabilidade e Estatística, Estância São Pedro.

Vygotsky, L. S. (1987). Thinking and speech: The development of scientific concepts in childhood. In R. W. Rieber \& A. S. Carton (Eds.), The collected works of L. S. Vygotsky, Volume 1, Problems of general psychology (pp. 167-241). New York: Plenum Press (original work published 1934).

Vygotsky, L. S. (1997).Genesis of higher mental functions. In R. W. Rieber (Ed.), The collected works of L. S. Vygotsky, Volume 4, The history of the development of higher mental functions (pp. 97-119). New York: Plenum Press (original work published 1931).

MARCOS NASCIMENTO MAGALHÃES

Department of Statistics

Institute of Mathematics and Statistics

University of Sao Paulo

Rua do Matão, 1010- CEP 05508-090

São Paulo, SP, Brazil 